\title{
Challenges to Urban Transport Sustainability and Smart Transport in a Tourist City: The Gold Coast, Australia
}

\author{
Tan Yigitcanlar ${ }^{*}, 1$, Lawrence Fabian ${ }^{2}$ and Eddo Coiacetto ${ }^{3}$ \\ ${ }^{I}$ Queensland University of Technology, School of Urban Development, Brisbane, Queensland, Australia \\ ${ }^{2}$ Trans 21, Boston, Massachusetts, USA \\ ${ }^{3}$ Griffith University, Griffith School of Environment, Brisbane, Queensland, Australia
}

\begin{abstract}
This paper aims to identify challenges to achieving sustainable and smart transport in a city whose form has been produced mainly by tourism urbanisation: the Gold Coast, Australia. The first part of the paper investigates urban transport sustainability, reviewing how urban density, travel behaviour and lifestyles, and the availability of various transportation services and modes influence urban transport sustainability. This is followed by an empirical analysis of transport trends, modal splits, and basic community profiles in the Gold Coast, to identify challenges to sustainable transport development therein. The paper also introduces and acknowledges potential positive outcomes of the current public transport policies and projects, and then explores the concept of smart transport focussing on automated people movers. The paper concludes by stating more actions for a sustainable transport system in the Gold Coast needs to be done including adaptation of smart transport options.
\end{abstract}

\section{INTRODUCTION}

Rising environmental concerns and problems have brought sustainable urban development in general, and sustainable urban transport in particular, to the agenda of almost every city across the world. Although there is no commonly agreed definition of sustainable transport, it is generally accepted that sustainable transport implies finding a proper balance between current and future environmental, social and economic qualities [1]. In other words, sustainable transport is that which satisfies current transport needs without jeopardising the ability of future generations to meet these needs.

The literature on sustainable transportation is vast and emanates primarily from Europe, North America, and Australia. Literature ranges from passenger issues [2] to transport sustainability issues [3]; from alternative transport models [4] to international transport sustainability practices [5]; from social change and sustainable transport [6] to accessibility planning [7] and impacts of mobility management projects [8]; and lastly from sustainable transport analysis frameworks and their innovative directions [9] to sustainable transport and quality of life [1], smart transport systems [10] and transport and land use planning integration [11].

Recent literature highlights five important issues confronting sustainable transport [12]. First, the petroleum upon which almost all (97\%) of our transport systems run is a finite resource. Indeed, some argue that peak oil production has already been reached [13]. Second, sustainable transport is environmental in its orientation and it deals almost exclusively with atmospheric pollution. This pollution includes

*Address correspondence to this author at the Queensland University of Technology, School of Urban Development, Brisbane, Queensland, Australia; E-mail: tan.yigitcanlar@qut.edu.au the excessive production of greenhouse gases that contribute to global warming, as well as the emissions that threaten the health and well-being of those who live in urban areas [14]. Third, many of our transport systems are congested, which is a critical problem in many major metropolitan areas around the world, also the transport disadvantage has become a critical problem for social inclusion and sustainable transport [15]. A fourth aspect is accidents and fatalities [16]. Fifthly and finally, a sustainable transport system must be judicious in its use of land and also not generate land sprawl and excessive related costs [17].

According to Nijkamp [18] and Shiftan et al. [19] the abovementioned five main factors influence the development of transportation; spatial and land use patterns; government policy; economic forces; technology; and social and behavioural trends. Each of these factors evolves over time and affects both each other and the transportation system. These factors also influence mobile technology, infrastructure design, travel behaviour, the level of motorisation, and policy measures and therefore will determine whether transport will be sustainable. Shiftan et al. [19] outline these five individual factors:

- $\quad$ Spatial and land use patterns: The demand for travel and thus the transportation system are influenced by the size of the urban area, building density, level of specialisation and the spread of activities within the urban area. Due to the long life span of buildings and infrastructure, the influence of spatial patterns on transportation is a long run one.

- $\quad$ Government policy: Authorities are strongly involved in transportation development for several reasons including the need for long range planning to reserve rights-of-way for future development, the huge financial investment and the consideration of negative ex- 
ternal effects. Thus, transportation development is sensitive to political priorities.

- $\quad$ Economic forces: Large-scale transportation projects are highly sensitive to economic changes because of the huge financial investment involved, the primary capital needed, the long time span of projects and the slow rate of returns.

- Technology: Technology can contribute to sustainable transportation by improving waste treatments and thus reducing pollution, as well as by offering substitutes to physical travel through communication. Technological development in transportation, however, is relatively slow, mainly due to reasons such as the scale and cost of the projects, the long time-frame of research and development, and the long life expectancy of infrastructure and mobile equipment.

- $\quad$ Social and behavioural trends: Individual behaviour is a combination of habits and of practical and emotional considerations. Thus, social values and norms may greatly affect the transportation choice of individuals.

Until recently compact city form has been seen as the most suitable for sustainable transport [20]. This involves high density development (i.e. for most Australian urban areas 50-100 persons/ha), close to or within the city core, combining a mixture of housing, workplaces and shops. Development of residential areas on the urban fringe, and single-family housing in particular, are strongly discouraged. Furthermore, centrally located high-density development supports a number of other attributes that are favourable to sustainable energy use: low energy use for housing and everyday travel, efficient remote heating systems, proximity to a variety of workplaces and public and private services, as well as a highly developed public transport system [21]. However compact city form is quite often criticised for not meeting some of the quality of life aspects, as it is rejecting suburban and semi-rural residential developments and neglecting the development of rural communities [22].

More recently various alternatives to the compact city form have been developed to try to combine the energy efficiency advantages of compact urban form with broader quality of life aspects. These alternatives include: the urban village [23]; new urbanism [24]; the sustainable urban matrix [25]; transit-oriented development [26], smart growth [27]; and decentralised concentration [28].

There is an increasing awareness that inefficient land use development within towns and cities, made possible by the automobile, is not sustainable in the long term. New emphasis is being placed upon the notion of integrated transportation, environment and land use planning, which is widely recognised as an essential precondition of sustainable development [11]. One of the imported approaches to this integration is promoting smart transport systems. Smart transport is a more environmentally friendly alternative to conventional public transport systems in that service frequencies, stop locations and coverage, and routing are more flexible. In some cases the vehicles are driverless. The smart transport systems (i.e. automated people movers, personal rapid transport) can be used in conjunction with conventional public transport systems (i.e. bus, light rail, heavy rail) to great ad- vantage as integral elements in a superior urban transport management system [10,29].

Low density (i.e. for most Australian urban areas 0-25 persons/ha) development is ubiquitous and is affecting urban transport sustainability and the quality of life in every region of Australia and many regions around the world. The problems may be exacerbated in cities with emerging urban forms such as those of cities characterised as being the product of tourism urbanisation - the process by which cities and towns are built or redeveloped explicitly for tourists [30]. For example, among other features, tourism urbanisation may be linear rather than focused concentrically around an urban core. Tourism urbanisation occurs in places such as southern Florida, Las Vegas, the northern Mediterranean coastline, and in eastern Australia on The Sunshine Coast and on The Gold Coast. This paper explores the challenges of achieving sustainable transport in Australia's premier tourist city, the Gold Coast located in the south-east corner of the state of Queensland. It also briefly considers the potential for the implementation of smart transport in this context.

As Australia's fastest growing local government area, the Gold Coast is just one case where low density urban development combined with high car dependency, poor public transport provision, lack of smart transport options and rapid growth is leading to problems like high emissions, waste and high traffic levels. To prevent these and ensure the Gold Coast remains a liveable region and an attractive destination for tourists, the focus of transport and urban policy needs to shift to improving the sustainability of transportation and urban development.

The paper is organised in five sections. Following this introduction, first, the paper explores urban transport and sustainability and other issues surrounding it, and its key determinants in the Gold Coast. Secondly, it presents and discusses the findings of an empirical analysis of transport trends, modal splits and community profiles in the Gold Coast to more precisely identify challenges to achieving sustainable transport in a city formed through tourism urbanisation. Thirdly the paper introduces and then explores the concept of smart transport focussing on automated people movers for the Gold Coast. Then the paper concludes with suggestions for a sustainable transport system in the Gold Coast City.

\section{URBAN FORM, TRANSPORT AND SUSTAINA- BILITY}

Following Shiftan et al. [19] the five main factors that influence the development of transportation as they apply to the Gold Coast local government area are briefly outlined in this section.

The area's spatial and economic developments are intertwined with each other and with its social character. It is characteristic of recent phases of capitalist development and typical of what was described some time ago as tourism urbanisation [31]. Its features include not only the lineal nature of growth and its underpinning by leisure oriented economic growth and immigration, but also its privately driven nature, relatively high levels of unemployment and a relative degree of volatility. The economy is also strongly underpinned by real estate development and investment, construction and 
immigration from southern states. Much of the recent property development is targeted at higher income markets. Along with the tourism industry, supporting service sector, small and medium size businesses, and newly emerging knowledge-based industries are among the major economic sectors of the Gold Coast.

The Gold Coast is renowned for its high rates of population growth underpinned by immigration. The local government area's 2006 population was 472,279, more than double what it was just eight years before at 214,949 [32]. Recent projections estimate the population will increase up to 800,000 people by 2026 although this figure does not include 60,000 visitors per night and six million day-trip visitors each year [33]. Its urban development is generally low density (0-25 persons/ha) and highly private motor vehicle dependent. Its eastern border is the beaches of the Pacific Ocean, the key tourist attraction. Otherwise, the urban area has no defined edge and can clearly be said to sprawl north, south and west. The broad pattern of growth is linear and comprises a series of north-south strips or band more or less parallel to the coast: the beach strip, tower/residential coastal strip, the highway strip, the canal estates, the suburbs and the semi-rural hinterland [34]. Major reasons for such a spreading development pattern are: wealthy baby-boomers' preference to choose the Gold Coast to spend their retirement; traditional suburban and car dependent lifestyle of most of its residents; availability of affordable land (until the 2001 property boom), and; previous local government development and planning policies.

Government policy historically has pro-actively promoted Gold Coast urban and land development. Major transport investments that have stimulated that development include the construction of the South East freeway in the 1980s to better connect Brisbane, the state's capital, and the Gold Coast and the freeway's major upgrade to four lanes completed in 2000. The major investment in public transport infrastructure has been the 2001 extension of Brisbane railways to connect Brisbane Airport, Brisbane and the Gold Coast terminating at the major privately created Robina residential and town centre development opened in 1996. This follows approximately the route of freeway. Largely however, local and state transport policy has not focused on public transport though there is a current rise in interest at the local level. Attempts to contain urban expansion have been minimal until the introduction by the Queensland Government of the South East Queensland Regional Plan in 2005 [35] to which local government planning schemes must conform. An important provision of the Plan and a significant departure from previous policy are statutorily enforceable urban footprints outside of which urban development are not to be permitted.

Public transport within the Gold Coast area is not highly developed. A recent study into public transport access showed marked spatial service variability and that good spatial and temporal access to transport is only for a minority [36]. Areas near the coast are better serviced and east-west access is particularly low. Some social groups like the young and low income groups have particularly poor access [37].

High car dependence is further demonstrated in the following analysis. This most likely engenders a culture of car dependence that hinders the capacity to introduce more environmentally friendly transport options.

\section{LAND USE AND TRANSPORT PATTERNS IN THE GOLD COAST}

This section provides a deeper analysis of transport, spatial and land use patterns. Specifically, a geographic information system (GIS) based spatial and statistical analysis is undertaken to explore transport sustainability in the Gold Coast using the 2006 Census, 2006 Journey to Work, 2003/04 Household Travel Survey data and land use, public transport and local zoning maps. This empirical research also benefits from the findings of previously conducted research $[35,36]$.

The Gold Coast, much like the rest of South East Queensland, is experiencing rapid population growth with diminishing household sizes. Additionally most people are living in detached dwellings. Apart from some high density (50-100 persons/ha) coastal strip locations such as Surfers Paradise, most of the suburbs have very low population and urban densities (Fig. 1). Urban density in the Gold Coast remains very low in comparison with other Australian cities and overseas regions [38]. The low urban density and population growth are leading to urban sprawl and scattered development.

The 2006 Census recorded over 280 thousand private motor vehicles $(286,386)$ in the Gold Coast, for a total population of slightly less than 480 thousand $(472,280)$. The Queensland Office of Urban Management's [39] research on travel behaviour predicted an increasing tendency in vehicle kilometres travelled (VKT) for the next two decades. This report indicated that unless any action is undertaken low urban density suburban development and rapid population increase will lead to record high figures of VKT by 2026 in South East Queensland.

One of the other prime reasons for the faster growth in VKT than the population growth is car dependency. VKT is a measure of car dependency and where it is high, VKT indicates a high concentration of unsustainable travel forms [40]. In no suburb of the Gold Coast is the minimum household motor vehicle ownership level less than 82 per cent, while in some suburbs this figure reaches up to 100 per cent. The total number of daily journey to work (JTW) trips on the Gold Coast is over 150 thousand $(155,986)$ and 91.2 per cent of these trips $(142,259)$ are made using private motor vehicles (Fig. 2). The average trip distance to work is 31.9 kilometres (one way), and so on average, Gold Coast people commute over nine million kilometres $(9,076,149)$ daily dominantly (91.2\%) using private motor vehicles.

The figures for commuting by a private motor vehicle vary between 80 and 97 per cent in the suburbs of the Gold Coast. Apart from some coastal and northern suburbs of the Gold Coast car dependency in JTW trips varies between 95 and 97 per cent. This is over 140 thousand $(142,259)$ cars on the Gold Coast roads everyday polluting the environment, causing congestion and accidents. This is also to say only a very marginal proportion (3-5\%) of the employees within these suburbs are using public transport or walking or cycling to work (Fig. 3). The reality becomes more alarming when one considers that JTW trips only constitute one-third 


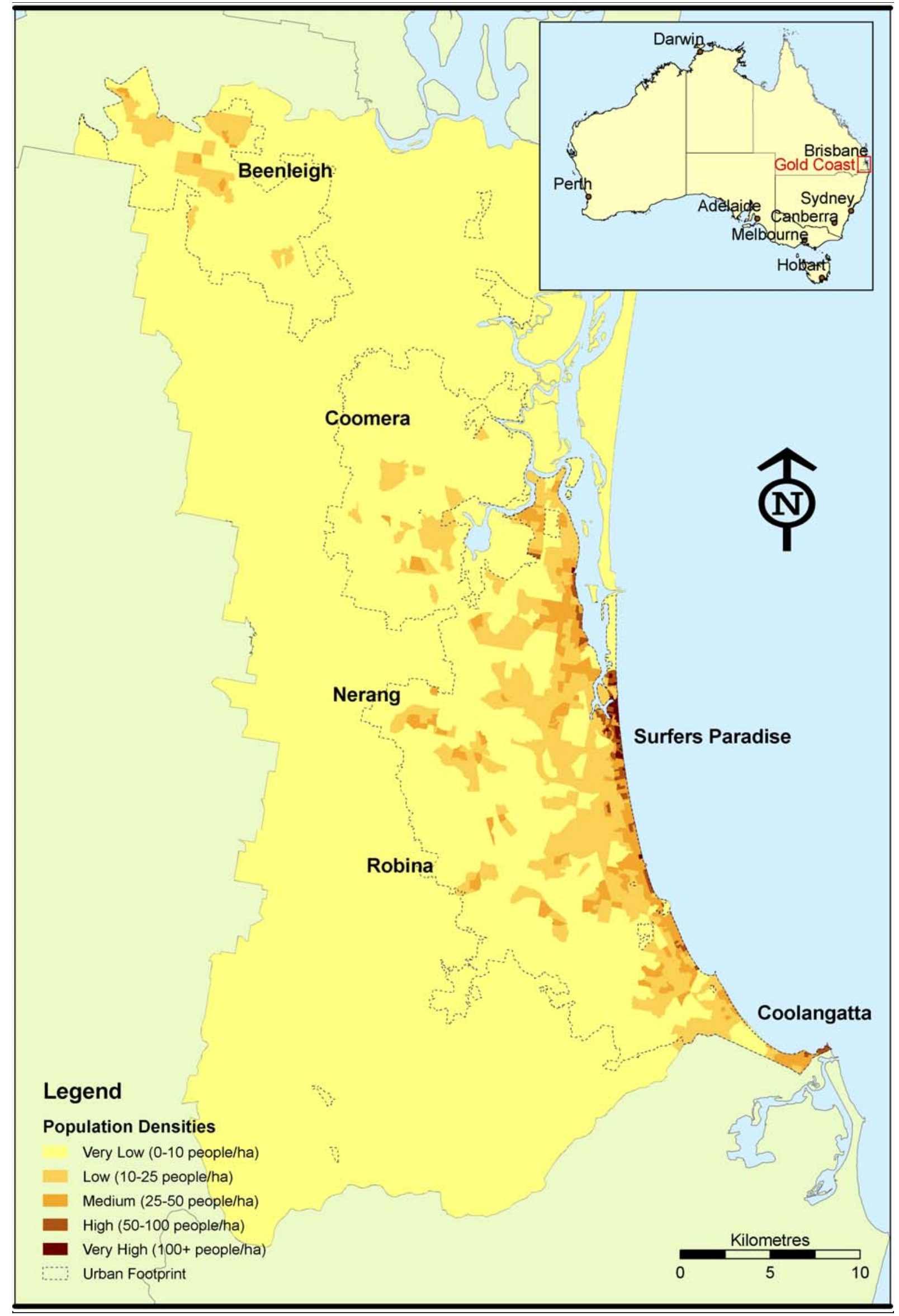

Fig. (1). Gross population densities. 


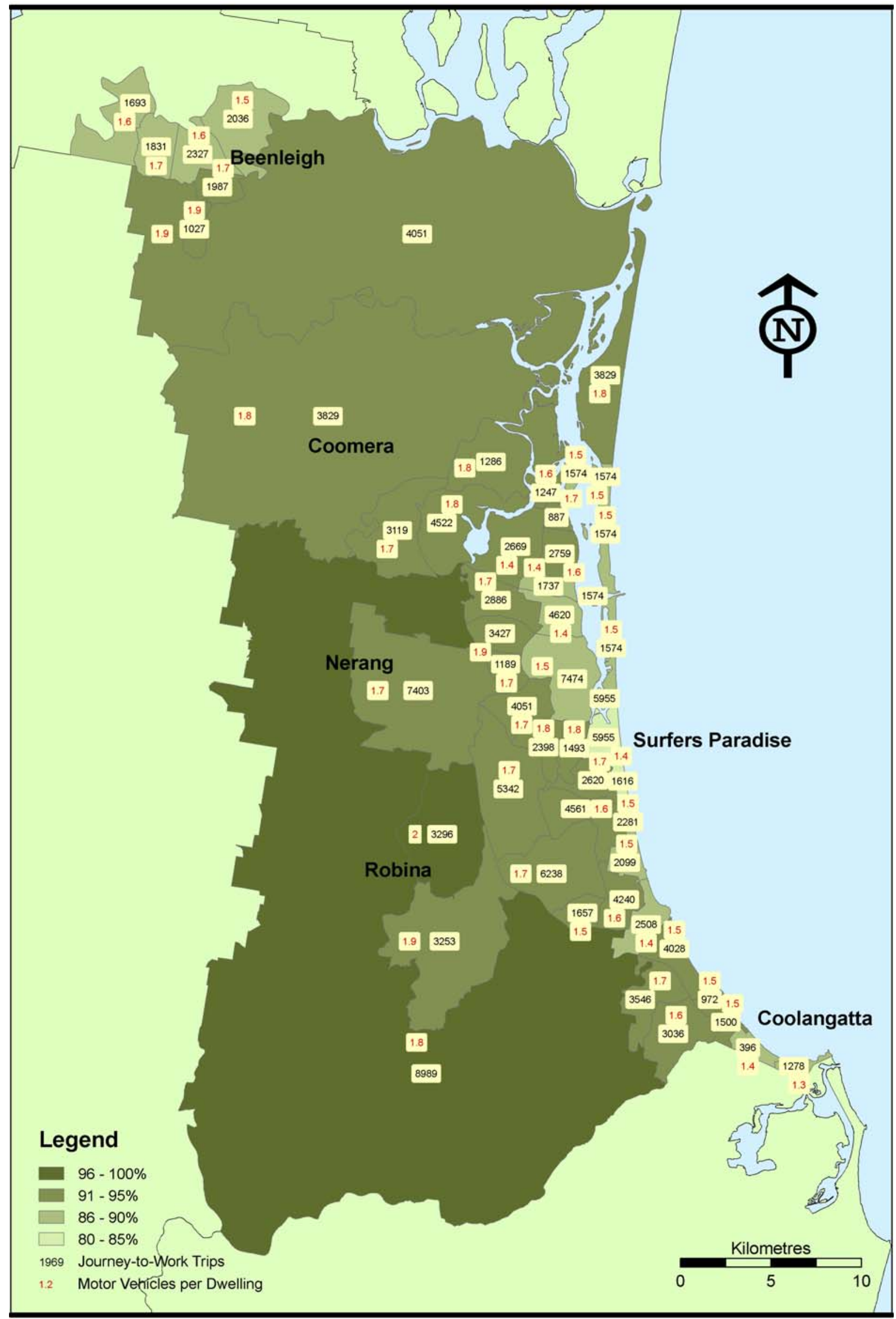

Fig. (2). Household motor vehicle ownership and JTW trips. 


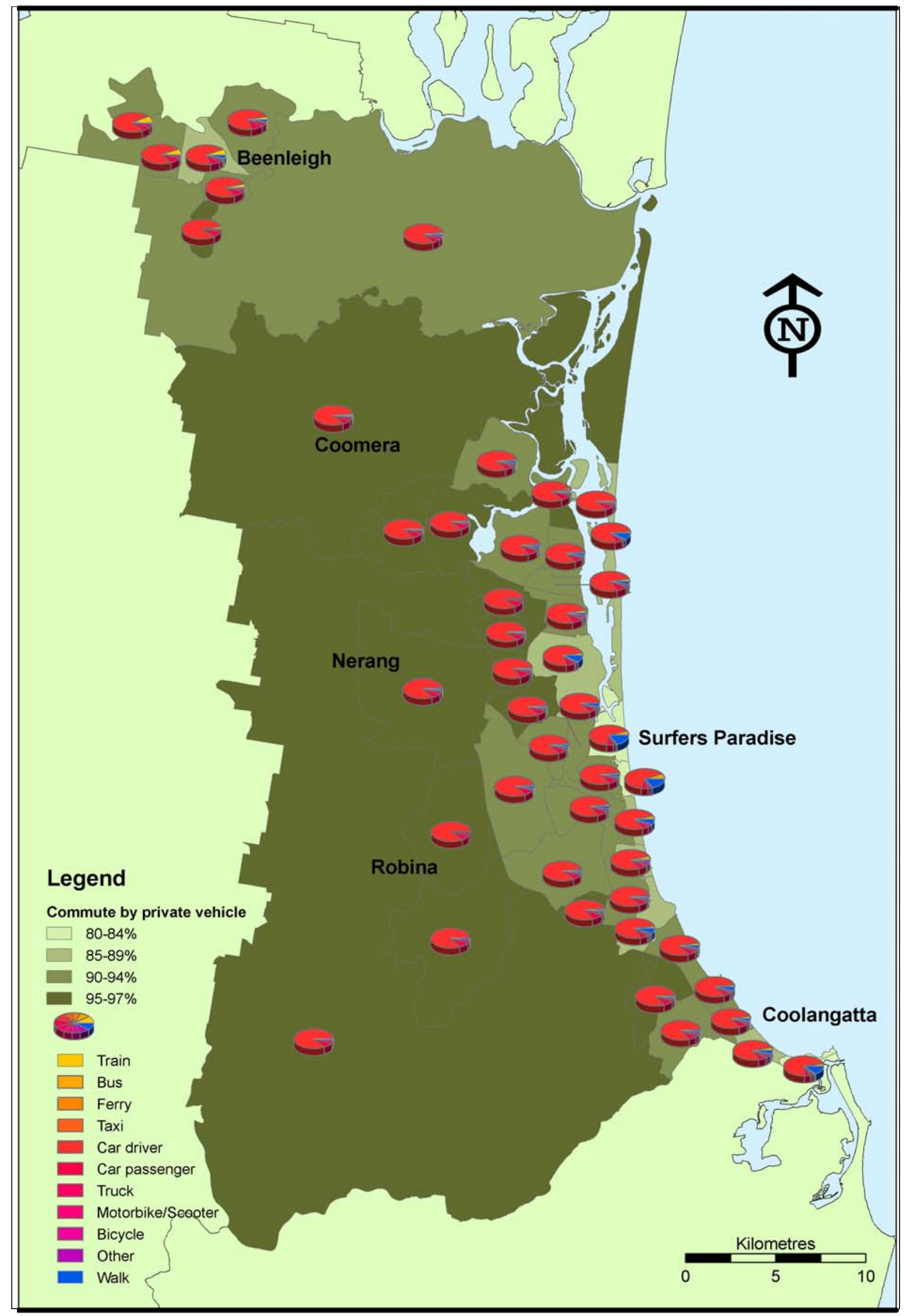

Fig. (3). Commuting by motor vehicle ownership and mode share. 
of the all trips, and these figures do not take daily around 60,000 visitors and their cars into account. A similar pattern applies to travel to school figures as well. The level of car dependency in journey to shopping and journey to recreational areas is also no less than that for journeys to work and school.

Queensland Transport's [41] comparison study on the mode share for South East Queensland between 1994 and 2005 has shown that the problem of unsustainable transport is chronic within the region. However the problem of car dependency is not unique to South East Queensland and the Gold Coast. Most of the Australian capital cities suffer from car dependency and unsustainable transport. According to Kenworthy et al. [42] the Brisbane metropolitan area, in South East Queensland, had the second highest share of private motor vehicle trips among Australian capital cities in 1995 following Perth, and this statement is still valid today. This share is less than some North American cities but much greater than many European cities.

Land use distribution in the Gold Coast confirms the existence of a scattered development pattern and with no defined urban boundary (Fig. 4). In combination, factors like car dependency, urban sprawl and low urban density impede the establishment of a successful public transportation network in the Gold Coast. Currently there are one train and 38 bus routes operating with approximately half hourly frequency during the day time in the Gold Coast (Fig. 5). When the existing public transport catchment areas are overlayed on the existing land use, large public transport gaps can be easily identified. Rural residential areas, western parts of the Gold Coast, in particular get poor, and in some cases no public transport services at all (Fig. 6).

In summary, the Gold Coast has many characteristics which combine and interact to pose major challenges to the development of sustainable transport. Therefore, the following challenging issues deserve attention:

- Urban development policy has traditionally proactively promoted Gold Coast's urban and land development with minimal attempts to contain expansion.

- $\quad$ The Gold Coast largely has a car oriented transport infrastructure and lacks adequate public transport infrastructure and services.

- $\quad$ Poorly developed internal public transport and public transport infrastructure, low service and patronage levels, and areas of public transport disadvantage have become characteristic of the Gold Coast. The most poorly serviced corridor is the east-west corridor, where western suburbs have largest acreage of residential development.

- There is a current strong emphasis and investment in inter-city public transport promoting further Gold Coast's urban and tourism development to the neglect of the rest of the local government area.

- High levels of car dependency are evidenced by several factors including rising VKT outstripping population growth, high levels of household vehicle usage, very high levels of vehicle patronage in all areas in JTW and in journey to school, and a transport modal split heavily biased towards motor vehicles.

- Traditional low density and scattered urban development pattern without strictly defined urban boundaries cause serious obstacles for the provision of a sound public transport with smart travel options.

On one hand, considering all these challenges, it is not surprising that in the Gold Coast transportation continues to be a serious urban problem. Particularly on the weekends, public holidays, school holidays, and summer season traffic congestion - caused by domestic, interstate and international visitors - becomes a critical problem. On the other, some attempts are being made to solve the Gold Coast's transport chronic problem. These include developing some state-ofthe-art computerised transport models focusing particularly on public transport and land use accessibility issues; promoting travel self containment; and introducing improved public transport services and smart transport to the Gold Coast. Some of these attempts are worth mentioning.

First, the Land Use and Public Transport Accessibility Index (LUPTAI) has been developed by the lead author of this article to measure and to develop integrated land use and transport strategies for the Gold Coast as there is a great scope to deliver the transport and land use outcomes outlined in the Regional Plan at the local level via Gold Coast's Local Government Management Strategies. The application of LUPTAI on the Gold Coast provides a mechanism to influence the development of the local government management strategies to deliver integrated transport and land use outcomes through a partnership approach between Queensland State Government Department of Transport and the Gold Coast City Council. LUPTAI is informing Gold Coast's local government management strategies development in the following ways [7]:

- Determining areas for potential transit-oriented development;

- $\quad$ Identifying areas with high accessibility due to public transport provision and land use mix where it would make sense to consider increasing population densities;

- Highlighting areas where low accessibility exists where it would make sense to improve public transport provision and/or land use mix; and

- Pointing out areas of social exclusion and transport disadvantage.

Second, in recent years Australia's urban policy makers have been revisiting the notion of local area self-containment and, more modestly, high travel self-containment as a key residential policy concern [43]. This is reflected in recent planning considerations in the Gold Coast through the new local government management strategies.

Third, recent discussions and projects on improving public transport on the Gold Coast, including smart transport options for the City, is another opportunity to overcome acute unhealthy urbanisation problems of the Gold Coast. For example, a rapid transit system, which is a dedicated 


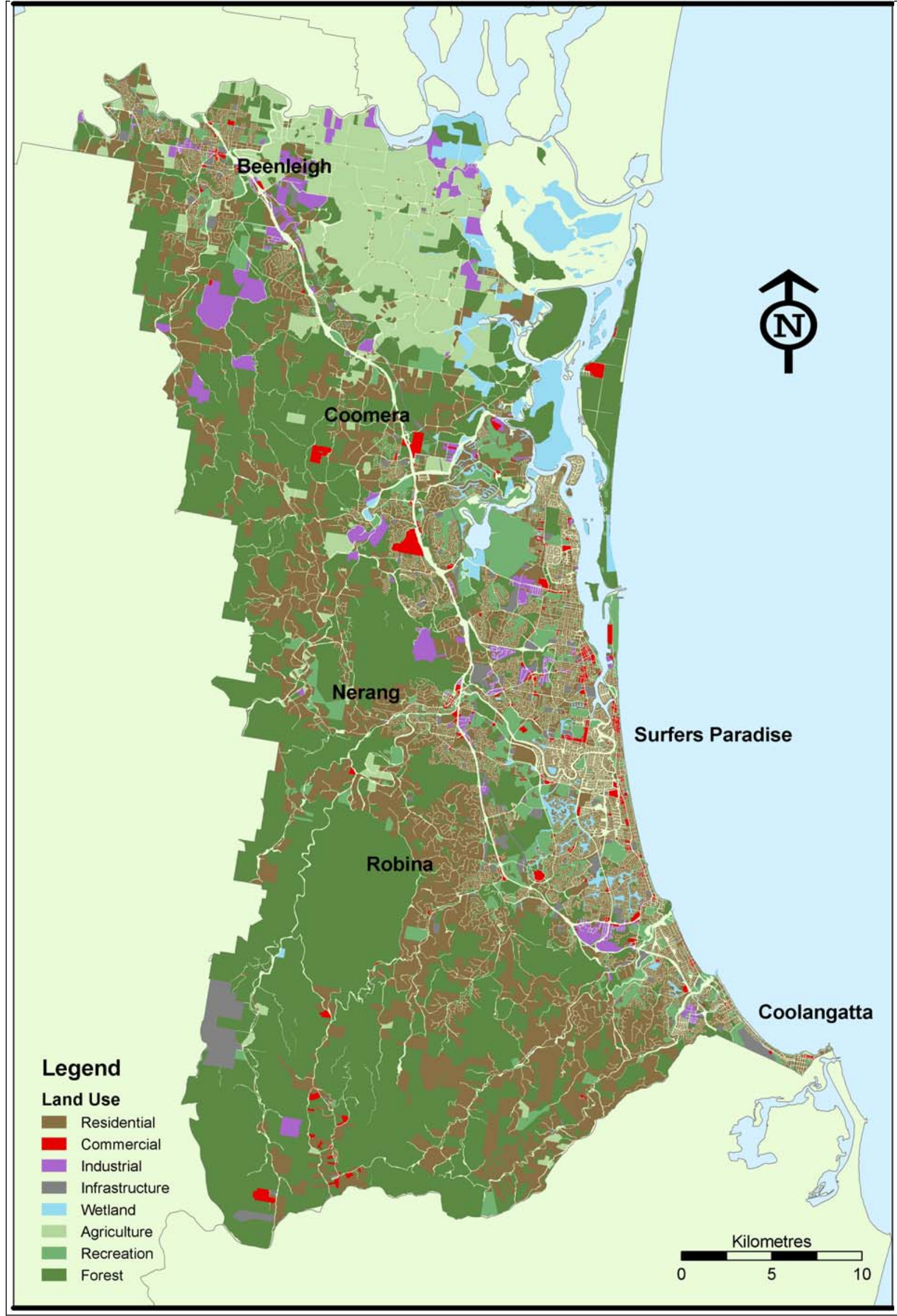

Fig. (4). Land use pattern. 


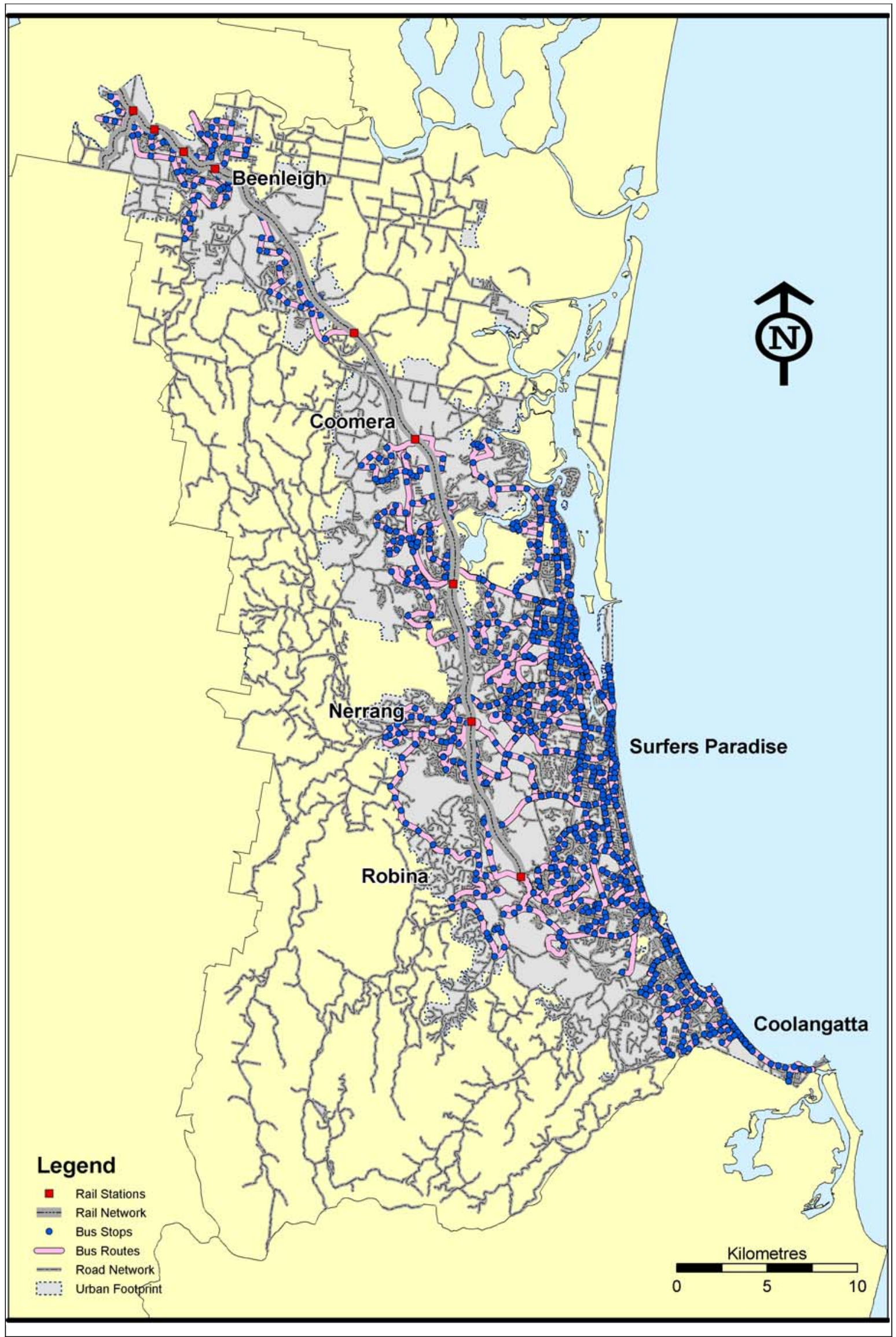

Fig. (5). Public transport and road networks. 


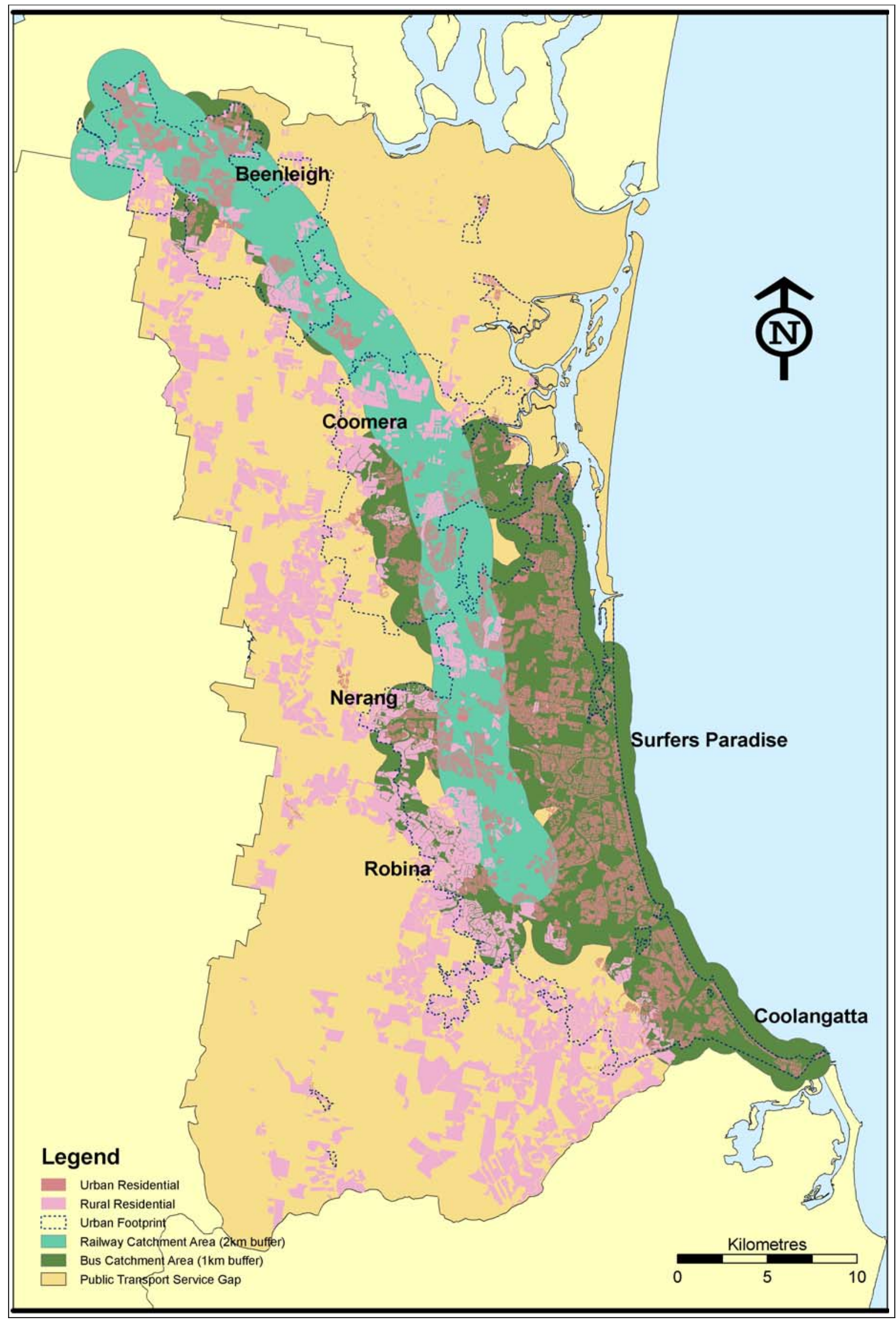

Fig. (6). Public transport service gaps 
transport corridor for use by modern high capacity vehicles (i.e. light rail or bus rapid), has been planned for the Gold Coast to provide a reliable system to help in overcoming major transport problems (e.g. congestion, accessibility, pollution). The planning stage of this $\$ 703$ million project is completed and construction is commencing in 2009. The first stage of this rapid transit system will connect Broadbeach at the centre of the City with Helensvale at the northern end of the City by 2011. The second stage which will connect Broadbeach with Coolangatta (airport) at the southern end of the Gold Coast is planned to be completed by 2015 [33]. This light rail project will also be supported with an efficient bus feeder system to connect light rail and heavy rail services (Fig. 7). When completed these improved public transport networks will service most of the urban footprint of the Gold Coast Local Government Area. However, the frequency and reliability of these public transport services will determine the sustainability outcomes of these investments.

Lastly, a number of policies are planned by the Queensland State Government Department of Transport and Gold Coast City Council to achieve a more sustainable transport system on the Gold Coast (Fig. 8). These policies include the following [33]:

- Progressively implement the rapid transit system offering high-frequency and quality services, develop major rapid transit stations as the primary transfer locations in the region, and construct park and ride facilities at strategic locations along the rapid transit system to reduce demand for parking in the city centre (Surfers Paradise);

- $\quad$ Upgrade the rail line to provide more frequent services, start progressive extension of the rail line to Coolangatta airport, construct new train stations, and incorporate major upgrades of existing key interchanges;

- Enhance local bus routes to train stations to provide quality connections between rail services, hinterland towns and coastal areas, integrate services and coordinate timetables at key transfer locations, and feed local services to key stations to provide effective links to key activity centres and line-haul bus and rail services;

$\bullet$

Upgrade stations and stops including improvements to bus shelters, access, security, signs and information display units, and also to improve access for people with a disability, construct signature bus stops along the key Gold Coast Highway corridor, and introduce real-time passenger information at key locations;

- $\quad$ Replace existing bus routes along the Gold Coast Highway with new routes as part of a major restructure to reduce route lengths and improve on-time running on the coastal corridor, and undertake a highoccupancy vehicle study to determine the need for bus lanes, transit lanes and other bus priority measures;

- Develop the inner north-south spines of the network, progressively implement high-frequency services on other east-west connections, and extend the local bus network into developing suburbs as early as feasible;
- Meet minimum standards for service coverage, frequency and operating hours across the urban areas, including introducing more evening and weekend services on all routes, and review and possibly restructure suburban routes to increase service frequency, provide weekend services and make services more reliable.

\section{SMART TRANSPORT OPTION FOR THE GOLD COAST}

During the last few decades technological change has so quickly transformed our lives and the demographic structure of our cities that is often difficult to gain a comprehensive perspective on it. While many city administrators are seeking more sustainable urban and transport development, technological developments are now providing new opportunities for cities in adopting better and smarter transport systems. Today technological change is enabling the automation of movements of trains, trolleys, and cars. It is unclear how these new forms of so called smart transport will evolve. Confined to tracks or guide ways, they are a new form of public transport. As automated highways, they are a hybrid of public and private transport sometimes called dual mode. However the general mistake we make is: seeing technology as the sole factor in forming the smart transport option. In a broad sense 'smart transport' is the design of urban environments, transport infrastructure and services, and communities to provide better accessibility to land use destinations with less use of private motor vehicles. This brings us the larger question of: what does this mean for urban sustainability?

The answer to that question is intimately tied to the issue of urban density. Mass ownership and use of private vehicles has led to suburbanisation and the emergence of exurban settlement patterns - very low density communities (0-10 persons/ha) but with full participation in social and cultural activities historically associated with cities. Our road-based mobility gives the means to live away from concentrations of people, but it also pushes us outward to sprawl because of traffic noise, air pollution, and the unpleasantness of parking when activities are concentrated.

Dual mode transport is an urban mobility concept in which cars can be inserted into guide ways for automatic control and parking. This has not yet emerged into reality. On the other hand, smart, fully automated transport is a small but growing reality. Automated people movers (APMs), known as advanced public transport systems or smart transport option, are normally relatively large vehicles (30-100 passengers) running on a special rail without driver, where the rail is normally structured as a simple line with online stations [44]. APMs also as heavy rail systems may typically carry considerably large numbers of passengers (hundreds).

At present there are about 130 APM installations in operation around the world moving about five million passengers daily. As shown in Table $\mathbf{1}$, about 30 percent of them are within and around airports, and the rest are mostly around dense urban centres (i.e. central business districts). About onethird of them are mass public transport of one form or another - driverless metros and district circulators. The rest are in private leisure and institutional settings. These prototype projects offer promising ideas for the planning of future sustainable urban and transport development. 


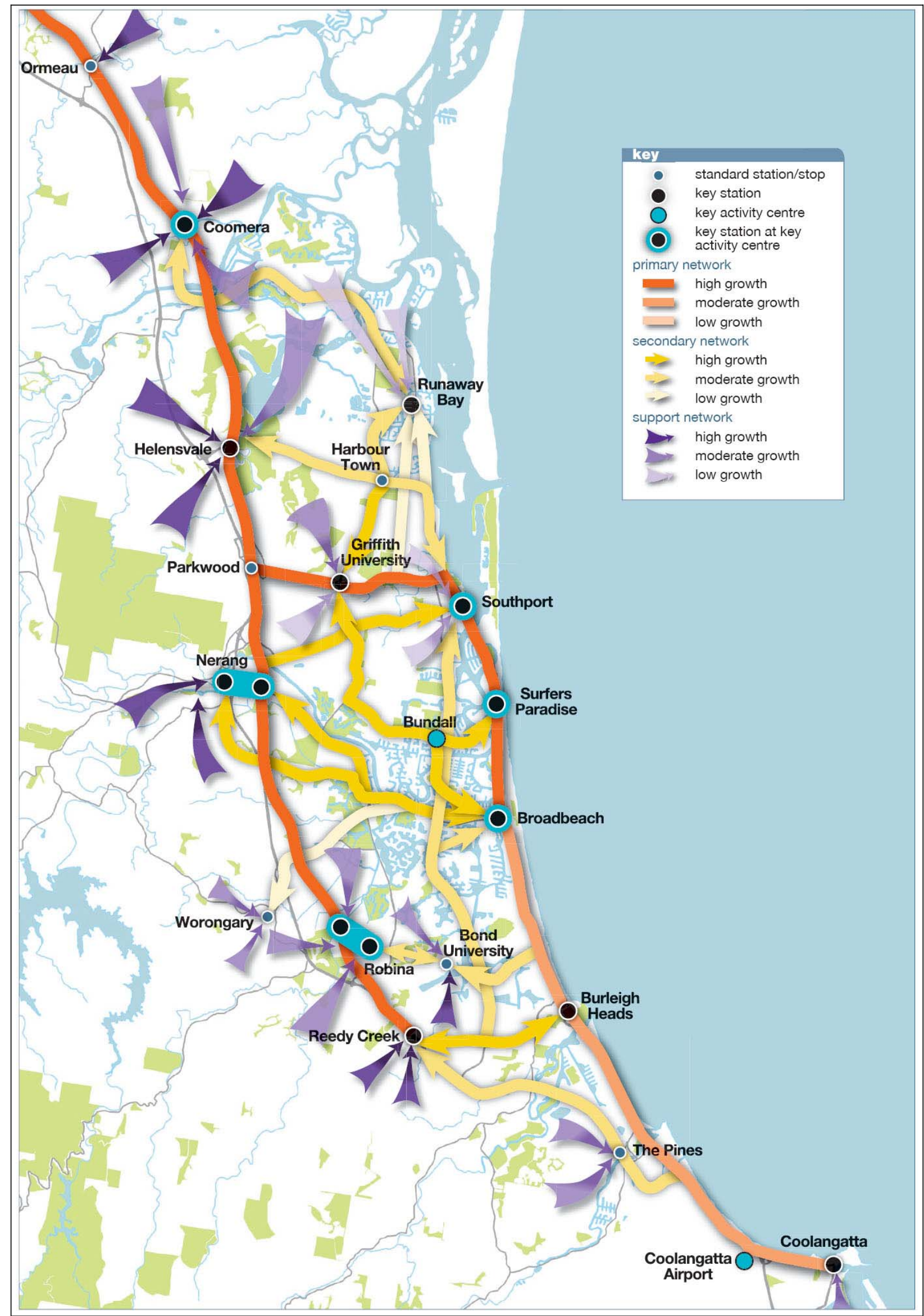

Fig. (7). Network strategy plan for public transport services [33]. 


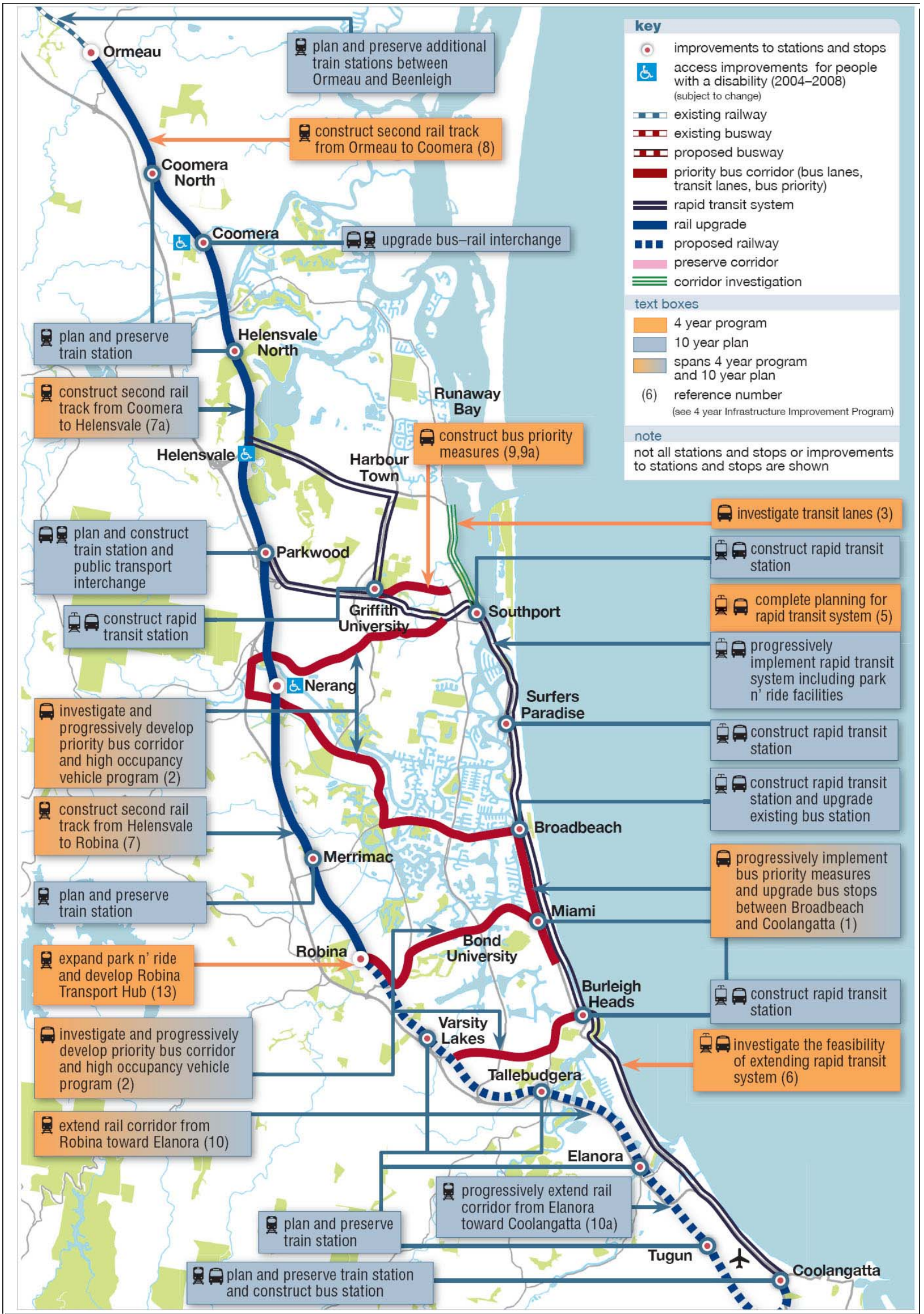

Fig. (8). Public transport infrastructure and service improvement plan [33]. 
Table 1. Automated People Movers [10]

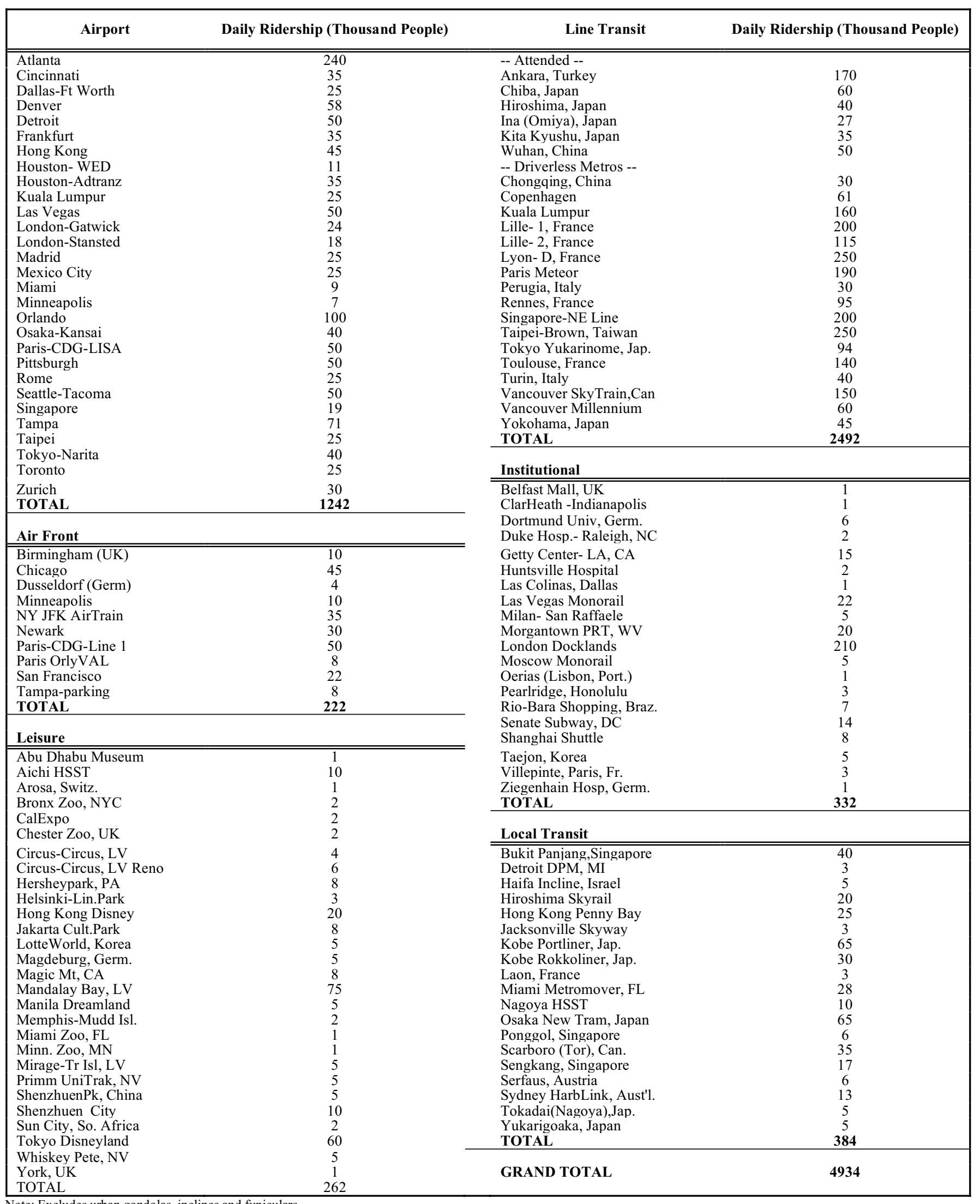

Note: Excludes urban gondolas, inclines and funiculars. 
Automation of trains and van-like vehicles means that the urban mobility services can be frequent and economic. This is not true for buses and conventional rail, for each 'run' requires the cost of a driver, resulting in a tendency to provide as few as acceptable. APMs eliminate this tendency, resulting in reduced wait times for passengers and making the service significantly more attractive to them. A fledgling APM industry has emerged, as witnessed by a series of conferences and standards organised by committees of the American Society of Civil Engineers [45]. Fabian [10,46] recently reviewed the APM industry and provided a list of active APM companies. The International Mass Transit Association has also noticed the accomplishments and potential of driverless metros progress and focused their attention on APMs [47].

Some APM concepts take the implications of automation a step further. They put stations off-line so that a very dense flow of vehicles is possible and so that each trip can be scheduled in real time without stops at intermediary stations. This is true not just for movements down a linear corridor, but also throughout a flexibly configured network. Known as Personal Rapid Transit (PRT), the service is more like automated taxis than driverless trains. Contrary to light or heavy rail APMs, PRTs could run feasibility over 3 or 4 passengers. Only one of the installations in Table 1 comes close to this - the Morgantown PRT. The service potential of PRT is significantly more attractive than most APMs - high enough that it can be expected to significantly affect the car ownership decisions and mode split patterns.

A linear APM monorail was planned by the Queensland State Government Department of Transport for the Gold Coast in the late 1980 s. Bids from four suppliers were received, but the project estimated to cost about $\$ 180$ million was not realised. The Gold Coast City Council explored feasibility of light rail in the late 1990s. Almost after two decades of delay, the construction of this rapid public transport system, with a modification to a light railway system, is starting in 2009 for the first stage of the system to be operationalised in 2011 and the final stage in 2015. During the last several years, Austrans, largest APM/PRT company in the Asia-Pacific Region, has analysed an installation of their APM/PRT technology on a eight kilometre, seven station route with lighter guide way and lower unit capital costs relative to conventional rail and monorail [48]. However the new rapid transit system project of the Gold Coast City has postponed consideration of this PRT project.

What APMs in general and PRT in particular mean for the sustainability of development of the Gold Coast is this: dense urban districts can be planned so that most mobility by non-automobile means is possible and attractive. People and business can be induced to prefer high density locations. Those that arrive by car can be intercepted in parking near regional roadways where they can conveniently transfer to smart transport which gets them to destinations in pedestrian-friendly, resource-conserving districts of density. Much like the other examples APM/PRT project of the Gold Coast (Smart People Mover project) could contribute to sustainability of the City (Fig. 9). With lighter guide way and lower unit capital costs relative to conventional rail and monorail, they estimate that a $\$ 1.85$ fare would generate enough revenue to cover operating costs and pay off the capital investment within ten years [484]. Implementation and expansion of such Smart People Mover projects across the Gold Coast City would definitely have a positive effect on the behavioural changes of the Gold Coast residents and also supports the tourism development and attraction of the city.

\section{CONCLUSION}

One of the major challenges for urban and transport planning is the problem that the continuous growth in traffic has had on the achievement of sustainable urban development [17]. The research reported here, therefore, explored transport sustainability in the Gold Coast. Like previously undertaken research $[35,36]$ our findings indicate that transport in the Gold Coast is not sustainable due to high level of car dependency, poor public transport services, low urban and population densities, and suburban and tourist lifestyles. This reflects the failure of previous transportation, land use and development policies of the State and Local Governments.

As suggested in the introduction, profound changes are required to engender a more sustainable transport system on the Gold Coast. A large part of this entails a shift to higher density living to facilitate better municipal servicing, including public transport services. Part of this is to be achieved through a reduction of urban sprawl properly sequencing development and containing it within clearly defined distinct urban boundaries since the development pattern is presently highly scattered. It remains to be seen whether the regulatory planning system can override the pre-eminence given to private interests in order to encourage such changes in land use. One promising approach would be to expand the roles of a recently established public land agency to organise the assembly and allocation of land to developers as occurs in other Australian states [46]. Given the aversion of private developers to risk and innovation, the agency could also play a demonstration role for other developers in the creation of well designed appealing medium-density (25-50 persons/ha) developments mainly to be located around transport hubs (i.e. major rail and bus stations). Through its greater control of land use and design over a larger area it could overcome the incapacity of small-scale, ad-hoc uncoordinated developments to create well planned, attractive, liveable environments. But creating more sustainable transport systems requires more than creating attractive medium density environments (i.e. transit oriented developments/communities). It may, for instance, require promoting a culture of courtesy to minimise noise, litter, odours and so on.

Current policies and the Gold Coast Rapid Transit Project seem to be a good step towards the right direction. However to achieve sustainability in the urban transport system in the Gold Coast there is more need to be done and planned, and firm targets should be set for a shift in the transportation modal split. This involves reversing the rise in private vehicle usage and reducing it from 80 per cent to perhaps very optimistically 50 per cent. Smart transport such as APM solutions (i.e. The Gold Coast Smart People Mover) could help public transport share currently at only eight per cent to be bolstered to perhaps 25 per cent. This would also help reverse the decreasing share of walking (11\%) and cycling 


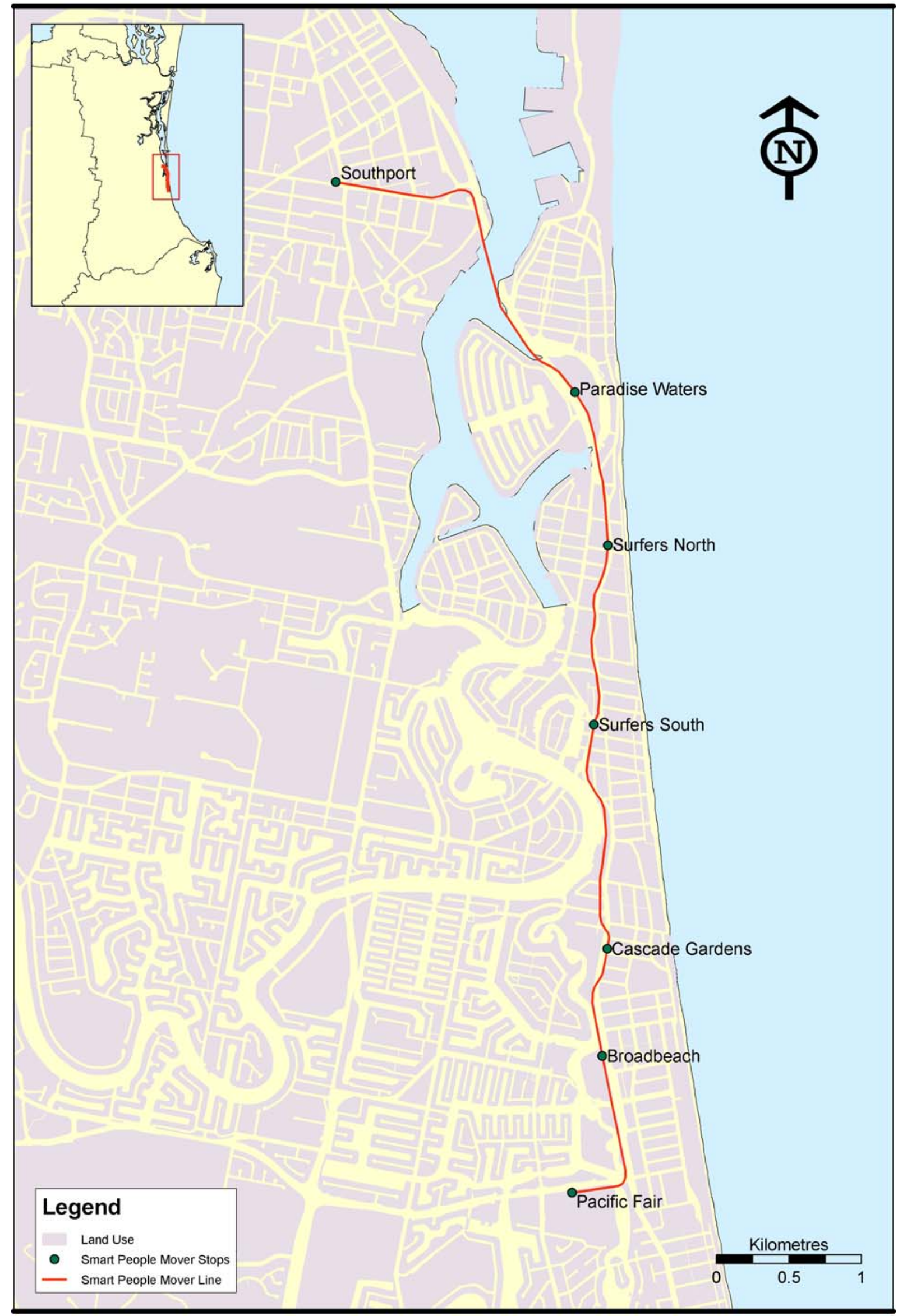

Fig. (9). Austrans Smart People Mover project proposal for the Gold Coast. 
(1\%), currently at 12 per cent, to bring up to perhaps 25 per cent. For sure changes in resident behaviours and urban form will not happen overnight, hence, but if planned and operated with supportive land use planning, along with a frequent and reliable conventional public transport system, APMs and PRTs can attract significant volumes of street traffic off the road and make for more sustainable cities. Relative to the poor public transport service levels currently in place, a far more ambitious public transport program is feasible if APMs are embraced and implemented.

\section{REFERENCES}

[1] L. Steg and R. Gifford. "Sustainable transportation and quality of life". J. Transp. Geogr. vol. 13, no. 1, pp. 59-69, 2005.

[2] B. Richardson, "Sustainable transport: analysis frameworks". $J$. Transp. Geogr. vol. 13, no. 1, pp. 29-39, 2005.

[3] R. Scrase. "Driving Freight Forward". ITS International, vol. 1998, pp. 47-51, 1998.

[4] B. Friedl and K. Steininger, "Environmentally sustainable transport: definition and long-term economic impacts for Austria". Empirica vol. 29, no. 2, pp. 163-180, 2002.

[5] E. Deakin, "Sustainable transportation: US Dilemmas and European experiences". Trans. Res. Rec., no. 1792, pp. 1-11, 2002.

[6] W. Black, and P. Nijkamp, (Eds.). "Social Change and Sustainable Transport". Bloomington, IN: Indiana University Press, 2002.

[7] T. Yigitcanlar, N. Sipe, R. Evans, and M. Pitot. "A GIS-based land use and public transport accessibility indexing model", Australian Planner, vol. 44, no. 3, pp. 30-37, 2007.

[8] A. Wilhelm, and K. Posch, "Mobility management strategies for the next decades: findings and recommendations from largest European Mobility management project". Transport. Res. Rec., no. 1839, pp. 173-181, 2003.

[9] T. Goldman, and R. Gorham. "Sustainable urban transport: Four innovative directions". Technol. Soc., vol. 28, no. 1, pp. 261-273, 2006.

[10] L. Fabian, "Planner's Guide to Automated People Movers". Trans.21. The 2007 edition. Boston, USA. Accessed on 11 April 2007 from www.airfront.us, 2007.

[11] H. Geerlings, and D. Stead, "The integration of land use planning, transport and environment in European policy and research". Transp. Pol. vol. 10, no. 1, pp. 187-196, 2003.

[12] W. Black, "Socio-economic barriers to sustainable transport". $J$. Transp. Geogr. vol. 8, no. 1, pp. 141-147, 2000.

[13] R. Heinberg, "The Party's Over: Oil, War and the Fate of Industrial Societies". New York: New Society Publishers, 2005.

[14] W. Black, and N. Sato, "From Global Warming to Sustainable Transport 1989-2006". Int. J. Sustainable Transp,, vol. 1, no. 1, pp. 73-89, 2007.

[15] Y. Duvarci, and T. Yigitcanlar, "Integrated modeling approach for the transportation disadvantaged", J. Urban. Plan. Devl., vol. 133, no. 3, pp. 188-200, 2007.

[16] E. Vasconcellos, "African Safety Promotion: equity, social differentiation, transport policy and road design" J. Injur. Viol. Preven. vol. 4, no. 1, pp. 52-69, 2006.

[17] D. Banister. "Sustainable urban development and transport - a Eurovision for 2020". Transp. Rev., vol. 20, no. 1, pp. 113-130, 2000.

[18] P. Nijkamp, "Sustainable transport: new research and policy challenge for the next millennium". Eur. Rev., vol. 7, no. 4, pp. 551677,1999

[19] Y. Shiftan, S. Kaplan and S. Hakkert, "Scenario building as a tool for planning a sustainable transportation system". Transp. Res. Part $D$ vol. 8, no. 1, pp. 323-342, 2003.

[20] K. Williams, E. Burton and M. Jenks, "Achieving sustainable urban form: an introduction". In K. Williams, E. Burton and M. Jenks (Eds.), "Achieving Sustainable Urban Form", London: E \& FN Spon, 2000.

[21] E. Holden and I. Norland, "Three Challenges for the Compact City as a Sustainable Urban Form: Household Consumption of Energy and Transport in Eight Residential Areas in the Greater Oslo Region”, Urban. Stud., vol. 42, no. 12, pp. 2145-2166, 2005.
[22] H. Frey, "Designing the City: Towards a more sustainable urban form". London: Spon Press, 1999.

[23] P. Newman and J. Kenworthy, "Sustainability and Cities: Overcoming Automobile Dependence". Washington, DC: Island Press, 1999.

[24] W. Fulton, "The New Urbanism". Cambridge, Lincoln Institute of Land Policy, 1996.

[25] T. Hasic, "A sustainable urban matrix: achieving sustainable urban form in residential buildings". In K. Williams, E. Burton and M. Jenks (Eds). "Achieving Sustainable Urban Form", pp. 329-336. London: E \& FN Spon, 2000.

[26] M. Boarnet and R. Crane, "Travel by Design: The Influence of Urban Form on Travel", New York: Oxford University Press, 2001.

[27] T. Stoel. "Reining in urban sprawl", Environment, vol. 41, no. 4, pp. 6-11, 1999 .

[28] E. Holden. "Ecological footprints and sustainable urban form", $J$. Hous. Built Environ., vol. 19, no. 1, pp. 91-109, 2004.

[29] L. Fabian, "Lifting the potential of public transport". American Planning Association. Accessed on 3 May 2006 from www.planning.org/hotopics/transport.htm, 2002.

[30] P. Mullins, "The evolution of Australian tourism urbanization". In L. Hoffman, S. Fainstein and D. Judd (Eds.), "Cities and Visitors: Regulating People, Markets, and City Spa". Oxford: Blackwell, 2003, pp. 126-142.

[31] P. Mullins, "Class relations and tourism urbanisation: the regeneration of the petite bourgeoisie and the emergence of the New Urban Form", Int. J. Urban Reg. Res., vol. 18, no. 4, pp. 591-597, 1994.

[32] Australian Bureau of Statistics 2008. "2006 Census Statistics". Australian Bureau of Statistics, Canberra. Accessed on 19 May 2008 from www.abs.gov.au.

[33] Translink, "Translink network plan: South East Queensland". Queensland Government, Queensland Transport, Brisbane, 2007.

[34] G. Griffin. "Where green turns to Gold: strip cultivation and the Gold Coast Hinterland". Transformation, vol. 2, no.1, pp. 1-15, 2002.

[35] Queensland Government, "South East Queensland Regional Plan 2005-2026". Brisbane: Office of Urban Management. Department of Local Government, Planning, Sport and Recreation, 2005.

[36] N. Buchanan, R. Evans, and J. Dodson, "Transport Disadvantage and Social Status: A Gold Coast Pilot Project", Research Monograph 8. Brisbane: Urban Research Program, 2005.

[37] J. Dodson, B. Gleeson, and N. Sipe, "Transport Disadvantage and Social Status: A review of literature and methods", Urban Research Program, Griffith University, Brisbane, Australia, 2004.

[38] Queensland Transport, "Smart travel choices for South East Queensland: A transport green paper". Queensland Government, Queensland Transport, Brisbane, 2006.

[39] Office of Urban Management, "South East Queensland Regional Plan 2005-2026". Accessed on 12 October 2005 from www.oum.qld.gov.au, 2005.

[40] S. Polzin, "The Relationship between Land Use, Urban Form and Vehicle Miles of Travel: The State of Knowledge and Implications for Transportation Planning", White Paper Prepared for the Florida Department of Transportation, University if South Florida, 2004.

[41] Queensland Transport, "South East Queensland Travel Survey 2003/04: Brisbane Statistical Division", Queensland Government, Queensland Transport, Brisbane, 2005.

[42] J. Kenworthy, F. Laube, and J. Vivier, "The UITP Millennium Cities Database for Sustainable Transport", International Union of Public Transport, 2001.

[43] T. Yigitcanlar, J. Dodson, B. Gleeson and N. Sipe, "Travel self containment in master planned estates: analysis of recent Australian trends", Urban Pol. Res., vol. 25, no. 1, pp. 133-153, 2007.

[44] E. Neumann, and M. Bondada, "Automated people movers: Engineering and management in major activity centres". Proceedings of a Conference sponsored by the Urban Transportation Division of the American Society of Civil Engineers, Miami, Florida, 25-28 March 1985, 1985.

[45] American Society of Civil Engineers, "Automated People Movers Proceedings series of Automated People Movers conferences", The American Society of Civil Engineers, Reston, VA, USA. Accessed on 10 May 2006 from www.asce.org, 2005.

[46] L. Fabian, "Planner's Guide to Automated People Movers". Trans.21. The 7th edition. Boston, USA. Accessed on 22 January 2006 from www.airfront.us, 2006 
[47] International Association of Public Transport, "Converting conventional metro lines into automated operation", Proceedings of the UITP Technical Workshop. Nuremberg, Germany, December, 2004. Accessed on 10 May 2006 from www.uitp.com, 2004.

[48] Austrans, "The Smart People Mover Gold Coast Project". Accessed on 16 May 2006 from www.austrans.com/presentations/GoldCoast pdf09Dec04.pdf, 2004.
[49] B. Gleeson and E. Coiacetto, "Public Land Agencies in Australia: The key to positive planning?" Urban Research Program Research Paper 5. Brisbane: urban Research Program, Griffith University, 2005.

(C) Yigitcanlar et al.; Licensee Bentham Open.

This is an open access article distributed under the terms of the Creative Commons Attribution License (http://creativecommons.org/licenses/by/2.5/), which permits unrestrictive use, distribution, and reproduction in any medium, provided the original work is properly cited. 